\title{
Simulation of Solidified Microstructure and Experimental Comparative Study of Twin-Roll Casting Aluminum Alloys
}

\author{
Teng Ma, ${ }^{1,2}$ Junting Zhang, ${ }^{3}$ Xiaochao Cui, ${ }^{1,3}$ and Xiaosi Sun ${ }^{1}$ \\ ${ }^{1}$ School of Materials Science and Engineering, Taiyuan University of Science and Technology, Taiyuan 030024, China \\ ${ }^{2}$ Huake Institute, Taiyuan University of Science and Technology, Taiyuan 030024, China \\ ${ }^{3}$ School of Applied Science, Taiyuan University of Science and Technology, Taiyuan 030024, China
}

Correspondence should be addressed to Xiaochao Cui; cuixiaochao@sohu.com

Received 12 April 2017; Accepted 18 June 2017; Published 2 October 2017

Academic Editor: Paolo Ferro

Copyright (C) 2017 Teng Ma et al. This is an open access article distributed under the Creative Commons Attribution License, which permits unrestricted use, distribution, and reproduction in any medium, provided the original work is properly cited.

\begin{abstract}
A coupled macro-micro mathematical model of twin-roll casting was established in the study. The continuous solidification process of Al-10Mg aluminum alloys in front of the nip point was numerically simulated by the cellular automaton method and the solidification microstructure, dendritic grain radius, and secondary dendrite arm spacing were obtained through simulation to predict the mechanical property of wedge strips. In order to verify the reliability of the simulation results, the metallographic examination and tensile tests were performed with the as-cast specimens. The results showed that the gain size, the distribution characteristics of various grain regions, dendrite arm spacing, and the yield strengths obtained from simulation were consistent with experimental results.
\end{abstract}

\section{Introduction}

Twin-roll casting is characterized by the short process, low energy consumption, and low manufacturing cost and widely used to produce aluminum alloy strips with good mechanical properties [1-4]. The solidification structure prepared by continuous casting affects alloy properties as well as the quality and mechanical properties of alloy strips [5-7]. Therefore, it is necessary to develop new rolling technologies and deeply explore the relationship between the casting process, solidification structure, and metal performance.

The solidification process of strips can be simulated with the computer simulation technology to study nucleation and grain growth and analyze solidification structure and geometric features. The formation process of the solidification structure can be displayed directly with the simulation technology. Several mathematical models were developed for the twin-roll casting process. Some micro mathematical models were established to simulate the evolution process of the solidification microstructure in a micro region by Liu et al. [8], S. D. Chen and J. C. Chen [9], and Huang et al. [10]. However, the complete solidification process of the strip or the prediction of mechanical properties of the as-cast alloy strip was not reported. The casting-state microstructure of aluminum alloy or other alloys had been explored in the twinroll casting experiments [11-13]. However, the solidification evolution was seldom explored.

According to cellular automata theory, the mathematical model of the solidification structure of twin-roll continuous casting was established in this study. With $\mathrm{Al}-10 \mathrm{Mg}$ aluminum alloys as the study target, the continuous solidification process in front of the nip point was numerically simulated in Procast. The dendritic grain radius and the secondary dendrite arm spacing were obtained to predict the mechanical properties of wedge strips. Finally, the mathematic model was verified through metallographic examination and tensile tests.

\section{Mathematic Models}

2.1. Macroscopic Model. Macro temperature field is the basis for simulating microstructures. According to the heat transfer process between the metal liquid, casting roller, and the 
environment, Xiong et al. proposed the mathematical model based on unsteady heat conduction [14]:

$$
\begin{aligned}
\rho c_{p} \frac{\partial T}{\partial t}= & \frac{\partial}{\partial x}\left(\lambda \frac{\partial T}{\partial x}\right)+\frac{\partial}{\partial y}\left(\lambda \frac{\partial T}{\partial y}\right)+\frac{\partial}{\partial z}\left(\lambda \frac{\partial T}{\partial z}\right) \\
& -\rho L \frac{\partial f_{s}}{\partial t}
\end{aligned}
$$

where $\rho$ is alloy density; $c_{p}$ is a specific heat at constant pressure; $\lambda$ is thermal conductivity; $L$ is latent heat; and $f_{s}$ is solid fraction.

\subsection{Microscopic Model}

2.2.1. Nucleation Model. During the twin-roll continuous casting, the undercooling of the liquid phase is generally far less than the undercooling required for uniform nucleation and liquid-phase surface oxidation, broken dendrites, and heterogeneous nucleation exist in the liquid metal. Therefore, the heterogeneous nucleation model is adopted to describe the solidification process of liquid metal. At a given undercooling $\Delta T$, the continuous nucleation model based on Gaussian distribution and proposed by Gandin and Rappaz [15] is adopted:

$$
\frac{d n}{d(\Delta T)}=\frac{n_{\max }}{\sqrt{2 \pi} \Delta T_{0}} \exp \left[-\frac{1}{2}\left(\frac{\Delta T-\Delta T_{N}}{\Delta T_{0}}\right)^{2}\right]
$$

where $\Delta T_{0}$ is the standard deviation; $n_{\max }$ is the maximum density of nuclei; and $\Delta T_{N}$ is the mean nucleation undercooling.

2.2.2. Growth Model. Twin-roll continuous casting is a nearrapid solidification process. Therefore, the modified KGT model is adopted to describe the constrained dendrite tip growth. The dynamic effect in the dendrite growth is not significant [16], so compositional undercooling and curvature undercooling other than the kinetic degree of the undercooling of dendrite tip are considered in the model. Assuming that the equilibrium distribution coefficient of alloy and diffusion coefficients of solute remain unchanged, the modified KGT model is given as [8]

$$
\begin{aligned}
\Delta T & =\Delta T_{c}+\Delta T_{R}, \\
\Delta T_{c} & =m c\left[1-\frac{1}{1-I v(\mathrm{pe})(1-k)}\right], \\
\Delta T_{R} & =\frac{2 \Gamma}{R}
\end{aligned}
$$

where $c$ is the solute concentration at the liquid interface; $k$ is the solute partition coefficient; (pe) is the Ivantsov function; and $\Gamma$ is the Gibbs-Thomson coefficient. According to the stability principle of the dendrite tip, the growth velocity of
TABLE 1: Chemical composition of Al-10Mg alloy.

\begin{tabular}{lcccccc}
\hline $\mathrm{Al}$ & $\mathrm{Mg}$ & $\mathrm{Si}$ & $\mathrm{Fe}$ & $\mathrm{Cu}$ & $\mathrm{Zn}$ & Other components $(\mathrm{Mn}+\mathrm{Ni})$ \\
\hline 89.70 & 9.90 & 0.11 & 0.18 & 0.01 & 0.03 & 0.01
\end{tabular}

dendrite tip $v$ and the growing radius of dendrite tip $R$ can be calculated as follows:

$$
\begin{aligned}
& R=2 \pi \sqrt{\frac{\Gamma}{m G_{c} \zeta_{c}-G}}, \\
& \mathrm{pe}=\frac{V R}{2 D_{L}}, \\
& v^{2}\left(\frac{\pi^{2} \Gamma}{\mathrm{pe}^{2} D_{L}^{2}}\right)+v\left\{\frac{m_{L} C_{0}\left(1-K_{0}\right)}{D_{L}\left[1-\left(1-K_{0}\right) I v(\mathrm{pe})\right]}\right\}+G \\
& \quad=0 .
\end{aligned}
$$

The secondary dendrite spacing is an important parameter to describe characteristics of solidification structure and can reflect the micro segregation and other casting defects. The secondary dendrite spacing, $\lambda_{2}$, is given as [17]

$$
\lambda_{2}=5.5\left(M t_{f}\right)^{1 / 3}
$$

where

$$
\begin{aligned}
& t_{f}=\frac{\Delta T_{0}}{G_{L} R}, \\
& M=\frac{T_{m} \Gamma D_{L} \ln \left(C_{f} / C_{0}\right)}{m_{L}(k-1)\left(C_{f} / C_{0}\right)},
\end{aligned}
$$

where $C_{f}$ is the final composition of liquid metal of dendrite root. The growth velocity of columnar crystals and dendrite tip as well as the dendrite spacing in the process of twin-roll continuous casting can be expressed by the modified KGT model.

\section{Experiment and Model}

3.1. Experimental. The alloy material used in the study is Al$10 \mathrm{Mg}$ aluminum alloy (Table 1 ). Aluminum ingot and magnesium ingot were melted in an airtight furnace according to the proportion of Al-10Mg aluminum alloy and inert gases were injected into the furnace to protect the melting process. The casting roller size is $\varnothing 400 \mathrm{~mm} / \varnothing 300 \mathrm{~mm}$; the roll gap width is $2-4 \mathrm{~mm}$; the gap between nozzle and roll is 0.10 $0.15 \mathrm{~mm}$. The chamber was preheated to $350 \sim 400^{\circ} \mathrm{C}$ and the temperature was maintained. Then the twin-roll caster was started and molten metal was poured into the chamber at the pouring temperature of $690^{\circ} \mathrm{C}$. The casting speed of the twinroll caster was $1 \mathrm{~m} / \mathrm{min}$.

When the aluminum alloy strip went through the rolling area, plastic deformation occurred and primary crystal shape was modified. In order to get initial solidification, the wedge strip was taken out after casting and processed to the length 
TABLE 2: Thermal physical properties of Al-10Mg alloy.

\begin{tabular}{lccc}
\hline Melting temperature $\left({ }^{\circ} \mathrm{C}\right)$ & Specific heat $\left(\mathrm{J} \cdot \mathrm{kgK}^{-1}\right)$ & Density of liquid $\left(\mathrm{kg} \cdot \mathrm{m}^{-3}\right)$ & Thermal conductivity of liquid $\left(\mathrm{W} \cdot \mathrm{mk}^{-1}\right)$ \\
\hline 607 & 1088.6 & 2.55 & 108.9 \\
\hline
\end{tabular}

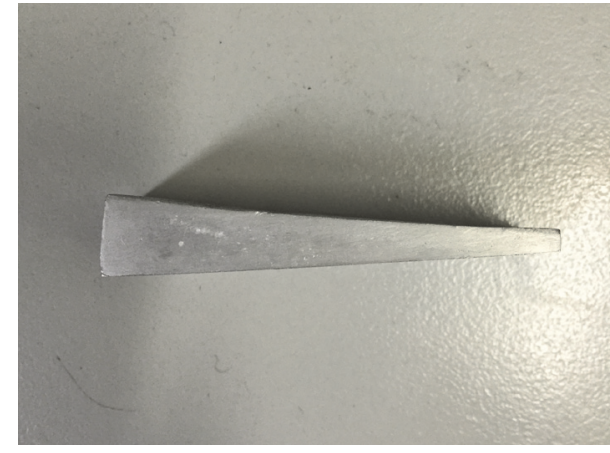

(a)

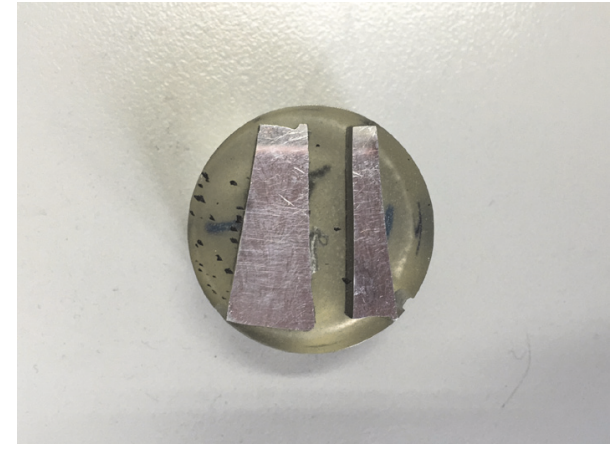

(b)

FIGURE 1: Twin-roll cast Al-10Mg alloy wedge-shaped plate specimen: (a) wedge-shaped plate; (b) mounting specimen.

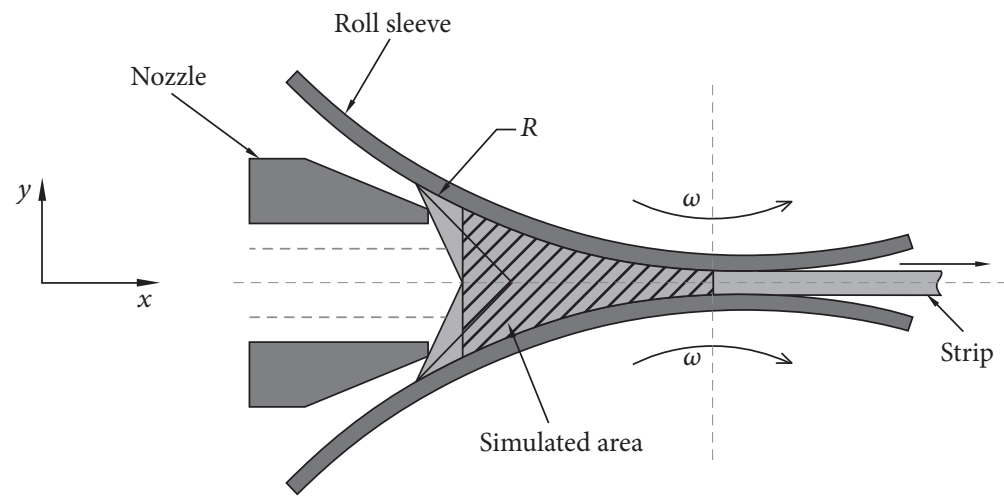

FIGURE 2: Diagram of the twin-roll casting process.

of $15 \mathrm{~mm}$ (Figure 1). After polishing, the strip was corroded in $50 \%$ HF. The rolled plane and the longitudinal section of the sample were observed by the metallographic microscope (LeiCADM2700M).

Three groups of standard samples $(10 \mathrm{~mm} \times 4 \mathrm{~mm} \times$ $3 \mathrm{~mm}$ ) were taken out along three directions: the horizontal direction, rolling direction, and the angle of $45^{\circ}$. The tensile tests were carried out with universal testing machine to obtain mechanical properties and stress-strain curve of $\mathrm{Al}-10 \mathrm{Mg}$ (strain rate $\varepsilon=5 \times 10^{-4} \mathrm{~s}^{-1}$ ).

3.2. Geometrical Model. In the process of twin-roll continuous casting, the continuous nucleation of the molten metal occurred at the meniscus of the roller when the rollers were reversely rotated. The cast-rolled strip was thickened constantly in the growth of dendrite. When the strip was close to the nip point, the solidification process was completed and the initial structure was formed. Therefore, the continuous solidification process in front of the nip point is numerically simulated in the study. The calculation area is shown in Figure 2 and the thermal physical properties of $\mathrm{Al}-10 \mathrm{Mg}$ alloy are shown in Table 2 [18]. The microstructure was analyzed and the mechanical properties were predicted. The simulation parameters were consistent with the production parameters. The thickness of the strip is $3 \mathrm{~mm}$. Figure 2 shows the schematic diagram of the twin-roll casting process. Under the conditions of continuous casting, the heat transfer in the roll barrel direction is far less than that in the other two directions. Therefore, the changes in the grain morphology mainly occurred in the longitudinal section and the rolled plane of the sample, but the grain morphology was the same in the strip width direction. Therefore, in order to simplify the model and reduce the calculation load, a certain section along the roll barrel direction was selected for analysis in the model under the assumption of adiabatic side seal. The strip width is $5 \mathrm{~mm}$ in the simplified model.

\section{Results and Discussion}

Figures 3 and 4, respectively, show the simulated and experimentally obtained microstructures of rolled plane and longitudinal section, which are $1 \mathrm{~mm}$ away from the roll in the continuous casting process. Figure 5 shows the schematic diagram of sample selection for microstructure 


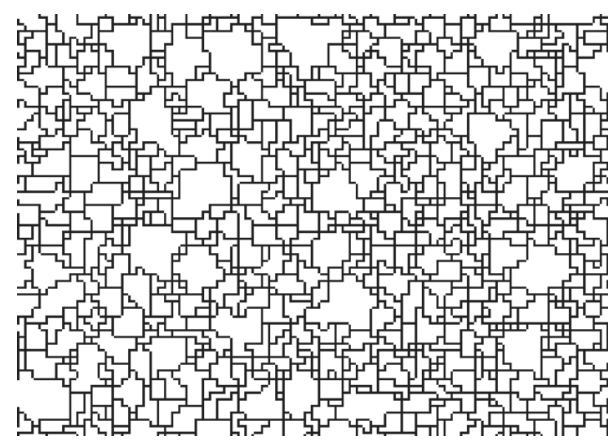

(a)

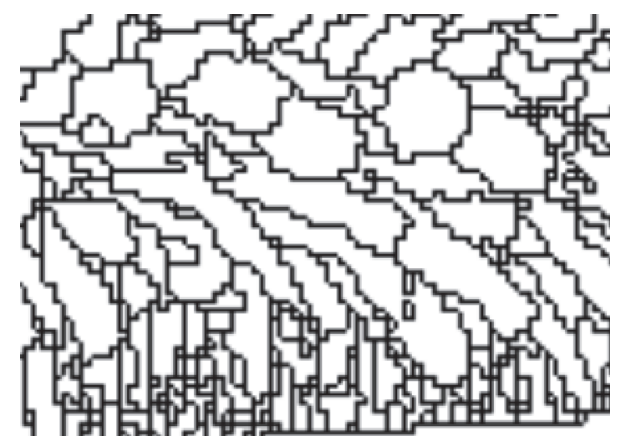

(b)

FIgURE 3: Solidification simulation of twin-roll cast Al-10Mg alloy wedge-shaped plate: (a) rolled plane; (b) longitudinal section.

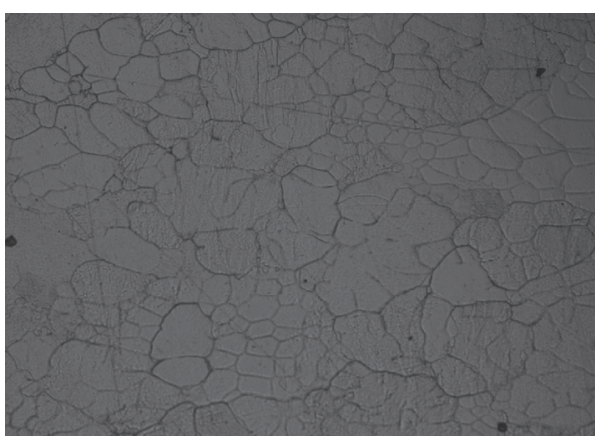

(a)

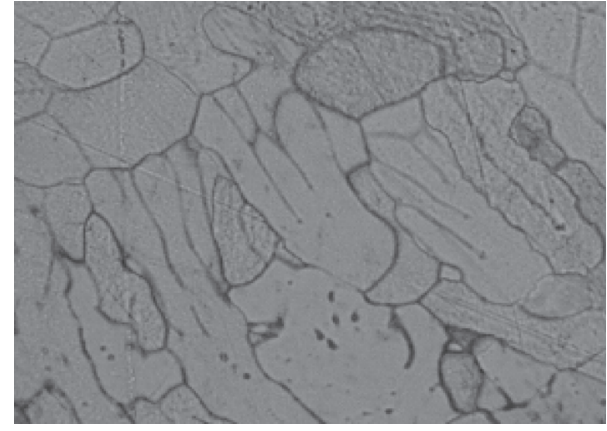

(b)

FIGURE 4: Solidification simulation of the cross section and lengthwise section of twin-roll cast Al-10Mg alloy wedge-shaped plate: (a) rolled plane; (b) longitudinal section.

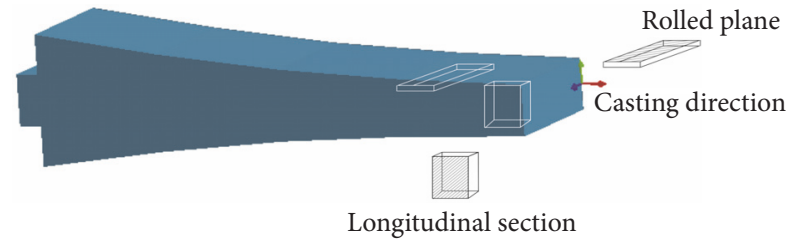

FIGURE 5: Schematic illustration of sample selection for microstructure and texture analysis.

and texture analysis. On the surface of rolled plane, the size of grains is uniform and equiaxed (Figure 3(a)). The grains near the casting zone are relatively larger (the left side of Figure 3(a)), whereas the grains near the rolling zone are relatively smaller (the right side of Figure 3(a)). In the simulation results, the grain size is $3.2 \times 10^{-8} \mathrm{~m}^{2}-4.9$ $\times 10^{-7} \mathrm{~m}^{2}$, whereas metallographic test results indicate that the grain size is $8.0 \times 10^{-8} \mathrm{~m}^{2}-8.1 \times 10^{-7} \mathrm{~m}^{2}$. The above results prove that the calculated results are well consistent with experimental results. The simulated grain size is a little smaller than the result by metallographic test because of the assumption made in the theoretical models. In addition, the solidification process is a complicated physical process and it is difficult to exactly determine the changing rule of thermal properties with temperature. In Figure 3(b), the solidification structure of longitudinal section from the roll surface into the strip center is, respectively, composed of the fine grain zone, columnar grain zone, and equiaxed crystal zone. The predicted results including the grain shape and grain size are consistent with the results of metallographic tests.

Figure 6(a) shows the fraction solid distribution of molten metal at the steady state. Figures 6(b) and 6(c), respectively, show primary dendritic radius distribution and secondary dendrite arm spacing distribution. The primary dendritic radius and the secondary dendrite arm spacing are important parameters for estimating the solidification structure and can reflect various roll casting defects. The solidification process of the solution reaches a stable state after the casting process becomes stable. The primary dendritic radius in the front of columnar grain growth zone reflects the growth condition of columnar grain growth. The smaller radius indicates the more obvious growth tendency. Figure 6(b) shows that the primary dendritic radius of strip surface is smaller than that of strip canter. As shown in Figure 6(c), the secondary dendrite arm spacing is gradually decreased from the outer zone to the inner zone along the thickness direction and is gradually increased from the outer zone to the inner zone along the rolling direction with the solidification. The largest secondary dendrite arm spacing occurs near the nip point and is about $19.55 \mu \mathrm{m}$. The measured result $(23 \mu \mathrm{m})$ in Figure $4(\mathrm{a})$ is basically consistent 


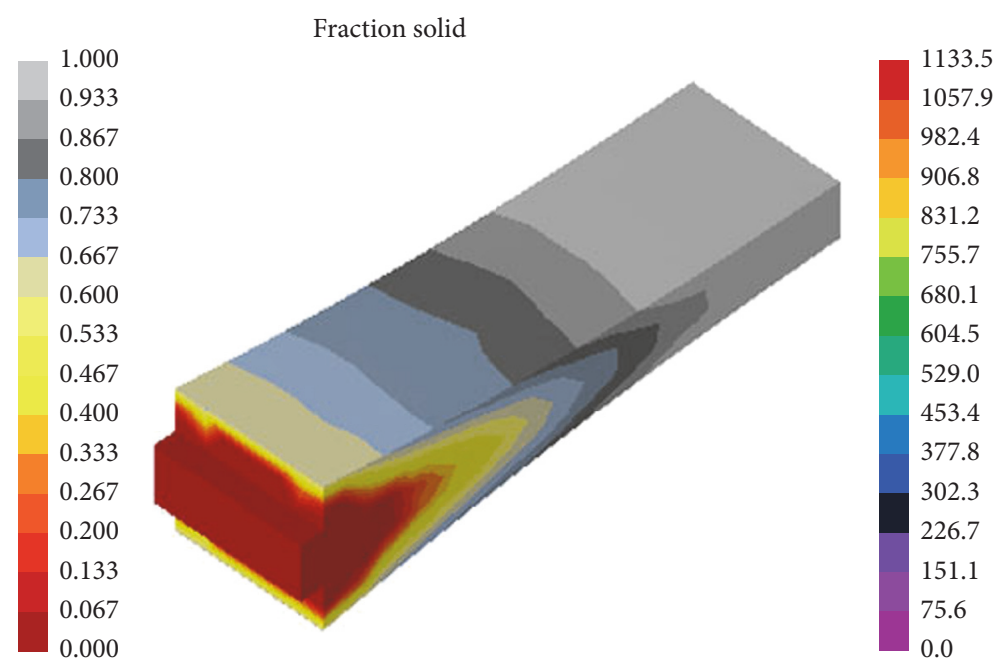

(a)

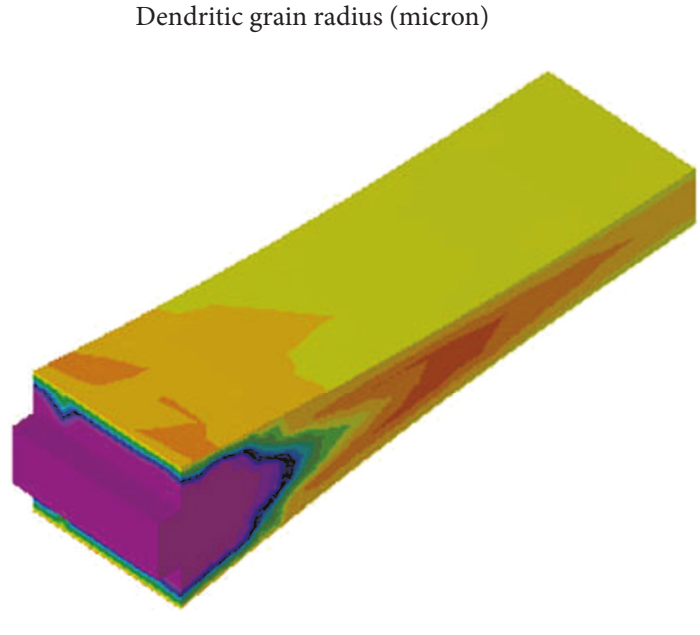

(b)

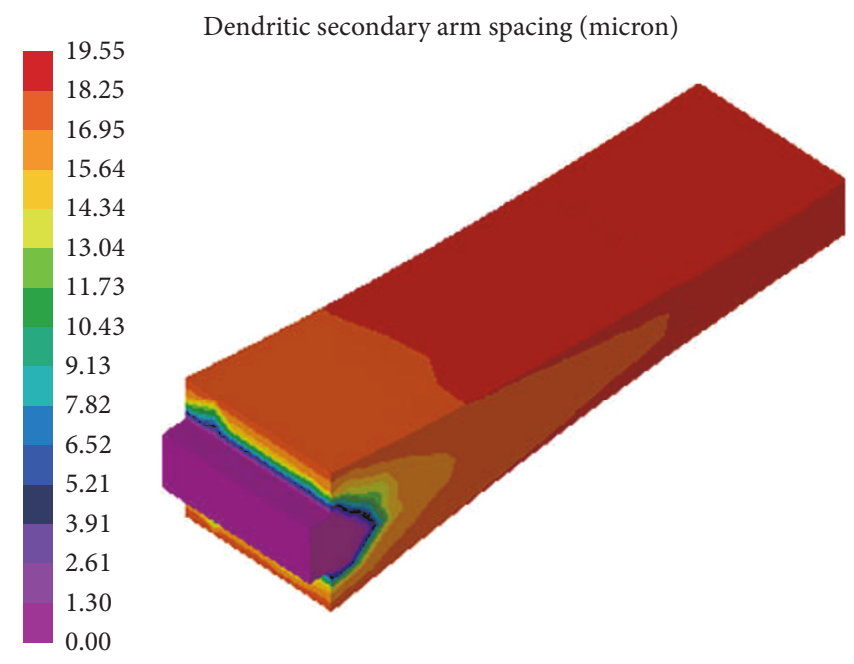

(c)

Figure 6: Solid fraction graph, dendritic grain radius graph, and secondary dendrite arm spacing graph of twin-roll cast Al-10Mg alloy wedge-shaped plate: (a) solid fraction graph; (b) dendritic grain radius graph; (c) secondary dendrite arm spacing graph.

with the simulation result, indicating that the model is applicable to predict the dendrite arm spacing.

Roll casting solidification is a sub-rapid solidification process. Compared with the traditional casting structures, the strip structure possesses the smaller grain size, lower segregation degree, and excellent mechanical properties. In this paper, the mechanical properties of the strip were predicted based on the solidification structure obtained by the mathematic model of the casting process. The predicted yield strength of twin-roll cast Al-10Mg strip was $158 \mathrm{Mpa}$, which was a little higher than the experimental result, $142 \mathrm{Mpa}$ (Figure 7), due to the defects such as segregation, gas cavity, and the heterogeneity of grain size. The experimental results of uniaxial tensile mechanical properties of $\mathrm{Al}-10 \mathrm{Mg}$ aluminum alloy casting strip at room temperature are shown in Table 3. The corresponding engineering stressstrain curve is shown in Figure 8. According to the above results, the Al-10Mg casting strip shows the good mechanical
TABLE 3: Tensile properties of twin-roll cast Al-10Mg plate.

\begin{tabular}{lccc}
\hline Orientation & $\sigma_{0.2} / \mathrm{MPa}$ & $\sigma_{b} / \mathrm{MPa}$ & $\delta$ \\
\hline $0^{\circ}$ & 142.9 & 207.2 & 8.6 \\
$90^{\circ}$ & 121.1 & 183.3 & 7.4 \\
$45^{\circ}$ & 108.6 & 159.4 & 5.3 \\
\hline
\end{tabular}

properties, obvious yield phenomenon, and higher elongation.

\section{Conclusions}

(1) A mathematical model of the solidification process on twin-roll continuous casting thin strip was developed based on the cellular automata (CA) theory. The continuous solidification process in front of the nip point was numerically simulated by Procast. The solidification microstructure, the 


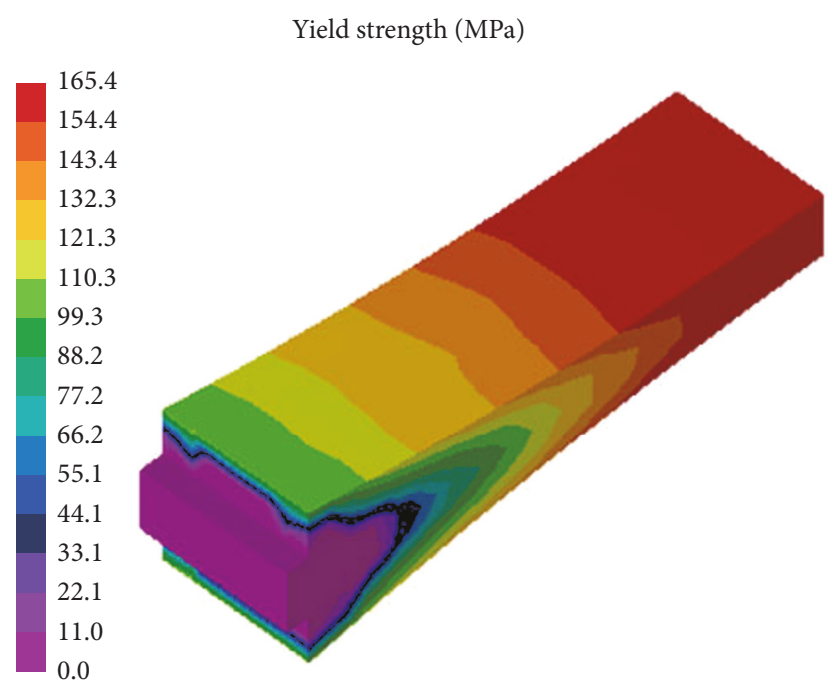

FIGURE 7: Simulation results of the yield strength of Al-10Mg alloy plate.

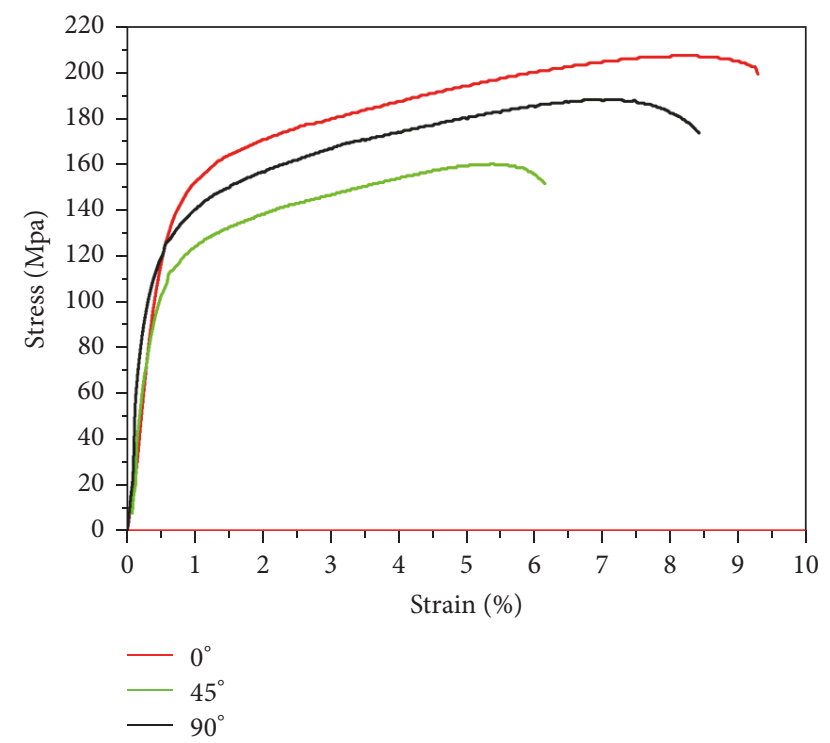

FIGURE 8: Engineering stress-strain curves of twin-roll cast Al-10Mg alloy plate at room temperature.

grains size, the dendritic grain radius, and the secondary dendrite arm spacing were obtained to predict the mechanical properties of the wedge strip.

(2) The simulation results were verified by metallographic examination and tensile tests. The simulation results of the microstructure on the wedge strip rolled plane and cross section, which was $1 \mathrm{~mm}$ away from the roll, were consistent with the experimental results. The simulation results of dendritic grain radius and the secondary dendrite arm spacing were, respectively, $1133 \mu \mathrm{m}$ and $16 \mu \mathrm{m}$, which were consistent with the experimental results. The predicted yield strength of the aluminum alloy strip was $158 \mathrm{MPa}$, which was consistent with the experimental results $(142.9 \mathrm{MPa})$.

(3) The solidification process of twin-roll cast alloy was described accurately with the established mathematical model. The model can be used to predict the solidification structure and mechanical properties of the strip under different process parameters and solidification parameters.

\section{Conflicts of Interest}

The authors declare that there are no conflicts of interest regarding the publication of this paper.

\section{Acknowledgments}

This work was supported by the National Natural Science Foundation of China (51574171 and 51641406) and the Natural Science Foundation of Shanxi Province of China (2015011002).

\section{References}

[1] P. D. Ding, B. Jing, C. M. Yang, and L. Fang, "Development and thought of thin-strip continuous casting," The Chinese Journal of Nonferrous Metals, vol. 14, no. S1, pp. s192-s196, 2004.

[2] H. S. Di, P. W. Bao, Y. C. Miao, G. D. Wang, and X. H. Liu, "Experimental study on the twin roll strip casting and analysis of processing stability," Journal of Northeastern University (Natural Science), vol. 21, no. 3, pp. 274-277, 2000.

[3] Y. Birol, "Analysis of macro segregation in twin-roll cast aluminium strips via solidification curves," Journal of Alloys and Compounds, vol. 486, no. 1-2, pp. 168-172, 2009.

[4] C. Gras, M. Meredith, and J. D. Hunt, "Microstructure and texture evolution after twin roll casting and subsequent cold rolling of Al-Mg-Mn aluminium alloys," Journal of Materials Processing Technology, vol. 169, no. 2, pp. 156-163, 2005.

[5] H.-L. Mao, J.-H. Wang, G. Yang, Q.-N. Shi, J.-H. Yi, and L.-W. Chen, "Characterization of microstructure of 1235 aluminum alloy sheet produced by twin roll casting," The Chinese Journal of Nonferrous Metals, vol. 24, no. 4, pp. 863-869, 2014.

[6] M. C. Flemings and R. W. Cahn, "Organization and trends in materials science and engineering education in the US and Europe," Acta Materialia, vol. 48, no. 1, pp. 371-383, 2000.

[7] K. Shibuya, F. Kogiku, M. Yukumoto, S. Miyake, M. Ozawa, and T. Kan, "Development of a rapid solidification process with a double-roller method," Materials Science and Engineering, vol. 98, pp. 25-28, 1988.

[8] X.-B. Liu, Q.-Y. Xu, T. Jing, and B.-C. Liu, "Microstructure of aluminum twin-roll casting based on Cellular Automation," Transactions of Nonferrous Metals Society of China (English Edition), vol. 18, no. 4, pp. 944-948, 2008.

[9] S. D. Chen and J. C. Chen, "Micro-model of simulation on twinroll continuous casting thin strip solidification structure," Rare Metal Materials and Engineering, vol. 42, no. 1, pp. 14-18, 2013.

[10] F. Huang, H. S. Di, and G. S. Wang, "Numerical simulation on solidification microstructure evolution in twin-roll casting process," Casting. Forging. Welding, vol. 40, no. 5, pp. 57-60, 2011.

[11] J.-H. Cho, H.-W. Kim, C.-Y. Lim, and S.-B. Kang, "Microstructure and mechanical properties of $\mathrm{Al}-\mathrm{Si}-\mathrm{Mg}$ alloys fabricated by twin roll casting and subsequent symmetric and asymmetric rolling," Metals and Materials International, vol. 20, no. 4, pp. 647-652, 2014.

[12] H. Harada, S. Nishida, E. Masaki, and H. Watari, "Casting of high-aluminum-content $\mathrm{Mg}$ alloys strip by a horizontal twinroll caster," Metallurgical and Materials Transactions B: Process 
Metallurgy and Materials Processing Science, vol. 45, no. 2, pp. 427-437, 2014.

[13] S. J. Yao, X. K. Wang, J. Xu, N. M. Han, and S. K Guan, "Microstructure analysis of cast rolling 1235 aluminum alloy plates," Light Alloy Fabrication Technology, vol. 42, no. 4, pp. 30-34, 2014.

[14] S. M. Xiong, Q. Y. Xu, and J. W. Kang, Modeling and Simulation Technology in Casting Process, China Machine Press, Beijing, China, 2004.

[15] Ch.-A. Gandin and M. Rappaz, "A coupled finite elementcellular automaton model for the prediction of dendritic grain structures in solidification processes," Acta Metallurgica et Materialia, vol. 42, no. 7, pp. 2233-2246, 1994.

[16] M. B. Yang, F. S. Pan, X. D. Peng, and P. D. Ding, "Macroscopic and microscopic coupling mathematical model," Journal of Chongqing University (Natural Science Edition), vol. 28, no. 5, pp. 39-44, 2005.

[17] B. Y. Sun, Direct Strip Casting of Metals and Alloys Processing, Microstructure and Properties, National Defense Industry Press, Beijing, China, 2014.

[18] B. Y. Hang, C. G. Li, L. K. Shi, G. Z. Qiu, and T. Y. Zuo, Chinese Materials Dictionary Book 4, China Material Engineering Canon, 2008. 

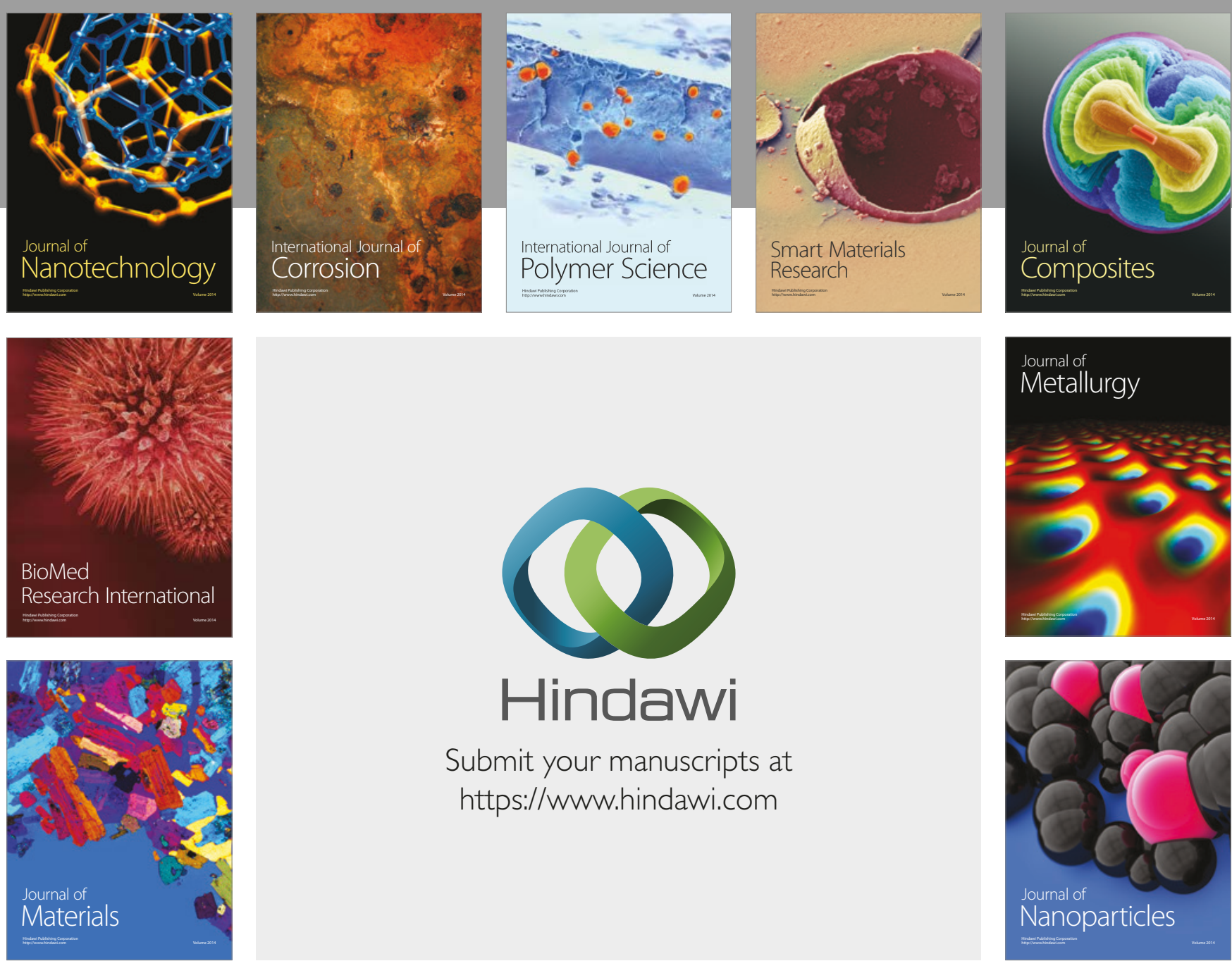

\section{Hindawi}

Submit your manuscripts at

https://www.hindawi.com
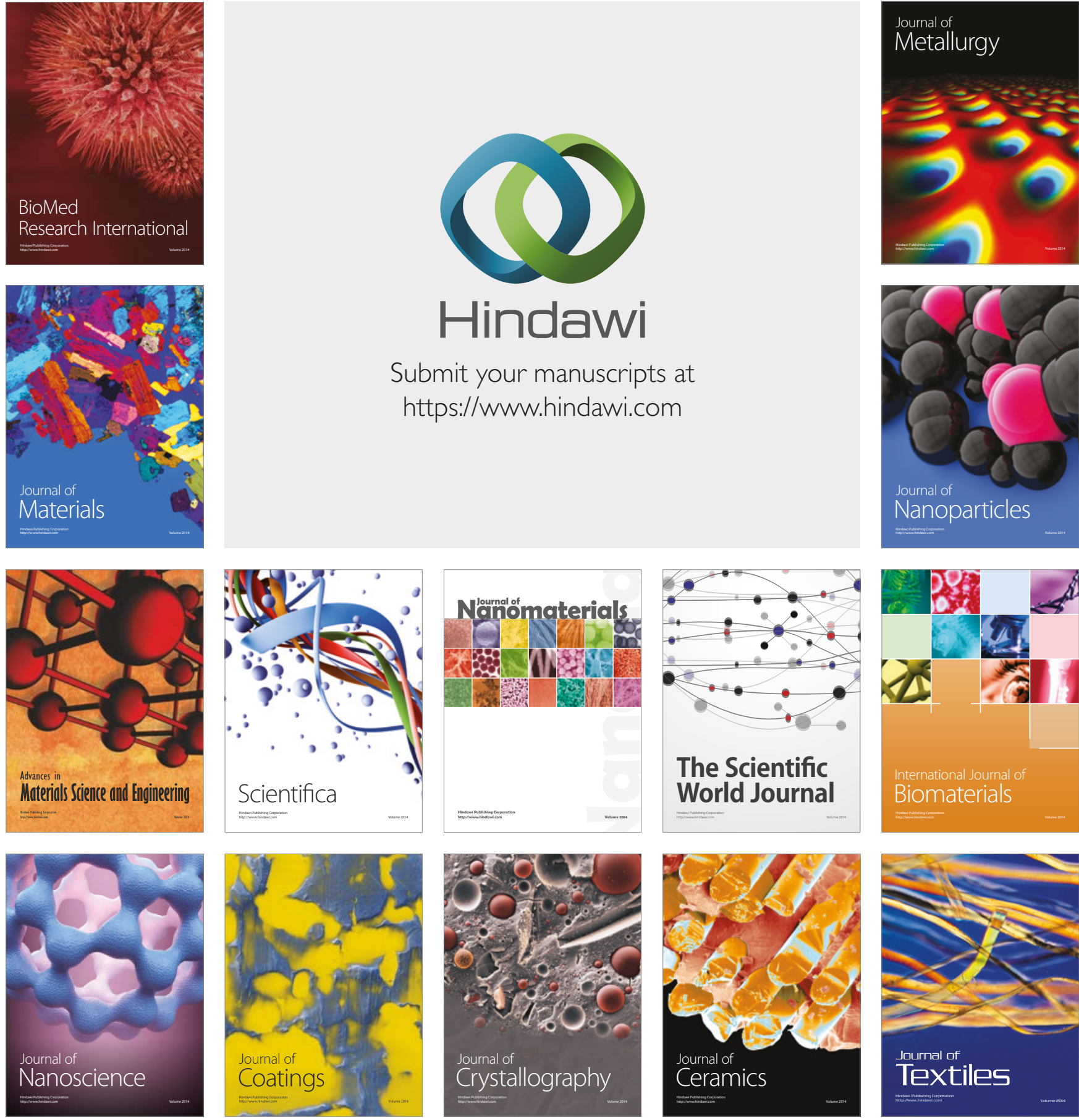

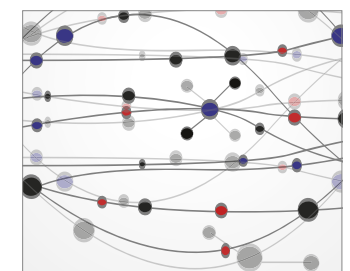

The Scientific World Journal
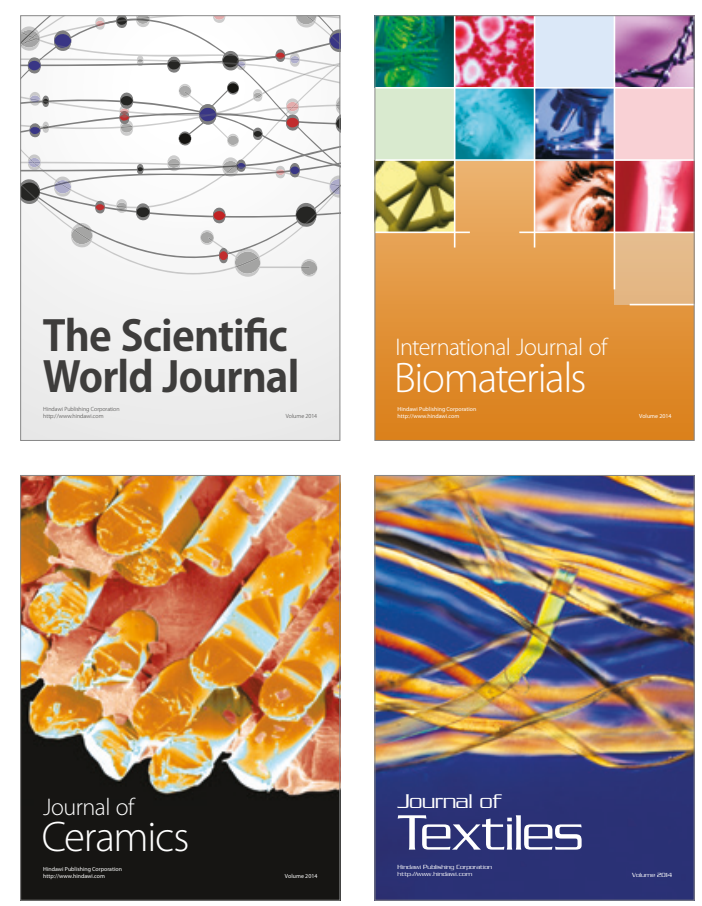